\title{
What do students and professionals think of BIM competence?
}

\author{
Yakamai, M, Singh, V and Suwal, S \\ Rakentajanaukio 4A, Otaniemi, Espoo- FI 02150 \\ Corresponding author: Vishal.Singh@aalto.fi
}

\begin{abstract}
Building Information Modeling (BIM) can have significant positive influence on the productivity and efficiency of construction projects. Hence, BIM competence is increasingly important in Architecture Engineering and Construction education. This paper aims to build a better understanding of BIM skills requirement to help the planning and implementation of BIM curriculum. A literature review was conducted initially to identify a set of BIM skills reported through previous studies. Thereafter, a questionnaire-based survey was conducted with students, researchers, and industry professionals to validate the identified set of skills, and assess respondents' perception of BIM competence and requisite skills. This paper presents the results from the survey.
\end{abstract}

\section{Introduction}

Building Information Modeling (BIM) is perceived differently by different trades within the construction sector. BIM today refers to a product (B-I-Model), an activity (B-I-Modeling), as well as a system (B-I-Management). The use of BIM in projects can have significant impact on quality, resource efficiency, and reduction in construction time and cost (Eastman et al, 2008). Research studies such as Gillian and Kunz (2007) have shown tangible benefits of BIM in projects. BIM can be used for various purposes throughout the project lifecycle, and increase the overall productivity. Since BIM relates to products, processes as well as people, the BIM way of working requires active collaboration and communication between the project participants. Team members from different disciplines need to work with BIM data, supported by the BIM professionals. BIM tools provide various possibilities for collaboration and exchange of data. A dedicated BIM manager for the projects is often seen as a requirement today. Thus, active cooperation between stakeholders is critical to successful BIM implementation.

Consequently, BIM education has become one of the key requirements in Architecture Engineering and Construction (AEC) education. BIM can empower the current and future AEC professionals to accomplish increase in productivity, waste reduction, and creation of a sustainable future through a combination of technical, methodological, procedural and organizational skills and competences. Thus, BIM education should also include individual as well as team skills and competences.

Nonetheless, because BIM is a relatively new topic in AEC education, and because the best practices in BIM education are yet to emerge, BIM courses are often taught as

adfa, p. 1, 2011.

(C) Springer-Verlag Berlin Heidelberg 2011 
technology training without any theory or collaborative learning. In contrast, industry values both technical as well collaborative skills, as the base for better integration and growth of the future employees (Ahn et al., 2012). Hence, the open questions are:

What is the right balance of technical and non-technical skills that BIM education should deliver? How do the combination of skills differ based on the desired role, for example, BIM manager, BIM modeler, etc? But, before we can answer these questions, we need to look at the following research questions:

1. What does the construction industry think about BIM competence?

2. Is BIM competence required for all AEC graduates?

3. What type of BIM competencies should the AEC graduates have?

4. What BIM competencies are needed for individuals, teams and organizations?

\section{Research method}

Initially a literature review was conducted, which was followed by empirical studies using an online questionnaire survey. The literature review provided necessary information on BIM, BIM skills, and BIM education. The survey questionnaire, based on the review, was used to collect primary data to understand the current perception of BIM competence among industry practitioners, students and researchers.

\subsection{Literature review}

According to Succar et al (2013) "Individual BIM competencies are the personal traits, professional knowledge and technical abilities required by an individual to perform a BIM activity or deliver a BIM-related outcome. These abilities, activities or outcomes must be measurable against performance standards and can be acquired or improved through education, training, and/or development."

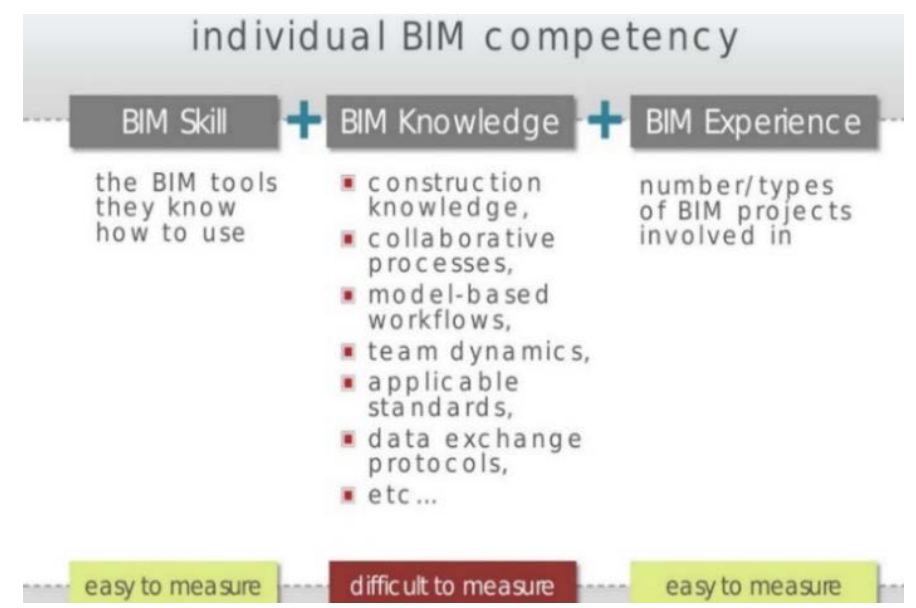

Fig. 1. Individual BIM Competence- (performance measurement \& improvement, Succar 2013) 
Several authors highlight the need for BIM skills in the AEC industry. For example, Fan et al., (2014) emphasize the need for a relationship between the BIM skills of a person and their understanding of intricacies of the field for which BIM is used. Mohd et al. (2013) mention that skilled BIM workforce helps in cost reduction and improved time management through clash detection. Wu and Issa (2014) anticipate BIM education as a solution to brisk up the BIM learning curve, though they recognize that the competencies of fresh graduates is not enough to satisfy the work-related demand. Instead, they suggest that BIM education prepares graduates to be ready to the extent that the organizations can shape BIM competencies of these graduates as per their own need.

Yarmohammadi \& Ashuri (2015) emphasize BIM competence regarding the coordination of building services, and how, a team leader with high BIM competence can have major impact on the progress and coordination of the project. Taiebat \& Ku (2010) report that the construction industry prefers to have future employees with deep conceptual knowledge of BIM rather than those with BIM application skills only.

A growing trend of new positions such as BIM professor and BIM manager shows the increasing need for BIM competent workforce. Project managers are likely to have a role as BIM managers. However, Rahman et al (2016) state that skill sets needed for project managers and the BIM managers are different. The authors also highlight that skills like teamwork and communication are required in the curricula.

Dossick et al. (2014) emphasize that BIM curriculum should also include the understanding of computer application concepts and BIM processes. Davies et al. (2015) also focus on the soft skills like collaboration and communication, negotiation, teamwork, leadership and conflict management. Similarly, Barison et al. (2011) look into individual competencies such as aptitude, qualifications, skills/abilities, knowledge and attitude, noting professional need for the position in both foundational and functional ways.

Table 1 summarizes the essential skills required for graduates, based on the review.

Table 1. - Summary of key BIM skills based on literature review

\begin{tabular}{l}
\hline Authors: BIM Competencies and skills \\
\hline Rahimi et al.2016: Teamwork, communication, understand BIM standards \& workflow. \\
\hline Succar et al.2012: Leadership, estimation, documentation \& detailing, model management. \\
\hline Eadie et al.2014: Collaboration \\
\hline Wei et al.2014: 3D coordination, modeling, design review, site utilization planning. \\
\hline $\begin{array}{l}\text { Murphy2014: Technical knowledge, planning \& administration, strategy \& policy, } \\
\text { programme management. }\end{array}$ \\
\hline Sturts et al.2014: Coordination and collaboration \\
\hline Davies et al.2015: Conflict management, communication, negotiation, teamwork, leadership. \\
\hline Barison et al.2011: Teamwork, leadership, analytical thinking, BIM applications, creativity \\
\hline Succar \& Sher2014: Leadership, collaboration, facilitation, organizational management \\
\hline
\end{tabular}

\subsection{Design of the questionnaire survey}

Based on the literature review, a survey questionnaire was designed with two sections: (1) BIM section and (2) BIM skills and competencies section. All the questions 
were mandatory to answer. Marginal questions such as gender and age were avoided. After asking about their role, respondents were prompted to select their professional background, and their work experience in BIM. Question 4 asked about the definition of BIM, where the respondents could choose one or more answers from a list of prestated definitions. Question 5 asked about the need for BIM competent employees in the industry. Questions 6 and 7 asked about the requirement for national level BIM competence certification, and who could be responsible for the certification. In the open-ended question 8, respondents could write their opinion about BIM skills and competences, fluency in BIM applications, knowledge of the development of BIM, and BIM experience. Using a 3-point scale, the respondents had to mark their answers as most or least important. Question 9 asked respondents about skills and competencies.

The second section of the survey continued with BIM skills and competencies. Multiple choices on BIM skills for BIM managers, BIM coordinator, BIM designer, and BIM team, based on the literature, were listed by the author for the respondents to rate on a scale of 10 , with 1 being the most important skill for the position and 10 as least important. Finally, in Question 14 the respondents were given a list of skills to choose from, and self-assess and rate their own competence levels in those skills.

\subsection{Data collection and survey results}

Around 105 emails were initially sent to BIM professionals and students. A link to the survey was also posted in BIM related groups in Linkedin.com. Respondents were assured that all the data collected from the survey will remain anonymized.

From the pool of 120 potential responses, the survey received 46 responses altogether. Thus, the final response rate at the time of closing the survey was $38.33 \%$.

\section{Section 1: BIM questionnaire.}

Figure 2 shows the breakdown of respondents. Others (e.g. BIM managers, project managers, consultants) and researchers were the most represented groups. Civil/ Structural Engineers and Construction/design/business managers were most common disciplinary backgrounds. In addition, Responses to Question 3 suggest that $82 \%$ of the respondents had reasonable (self-assessed) experience with BIM, showing that BIM has become popular in the AEC industry.
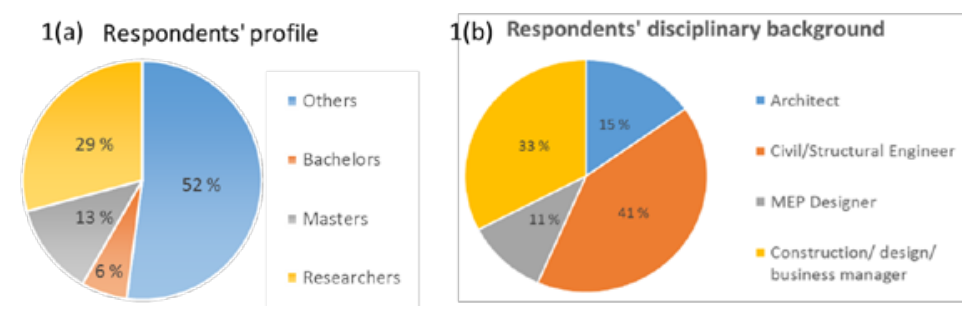

Fig. 2. Respondents profile based on questions 1 and 2 in the survey

In Question 4, four pre-defined options were given to choose from, Figure 3. Most respondents selected option $\mathrm{D}$, indicating that the wider view of BIM is more prevalent. 


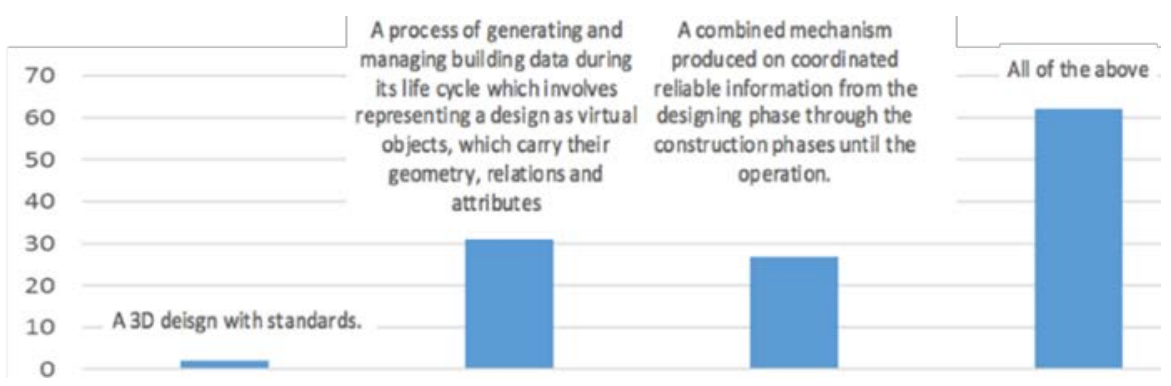

Fig. 3. Description of BIM

As seen in Figure 4, 80\% respondents see the need for BIM competent engineers. More than $50 \%$ see the need for certifications systems, while $16 \%$ feel it is not required. The respondents suggest that educational bodies and professional associations should provide BIM competence certification. Others suggest EU level certifications. Around $20 \%$ think that the BIM application vendors should provide competence certifications.

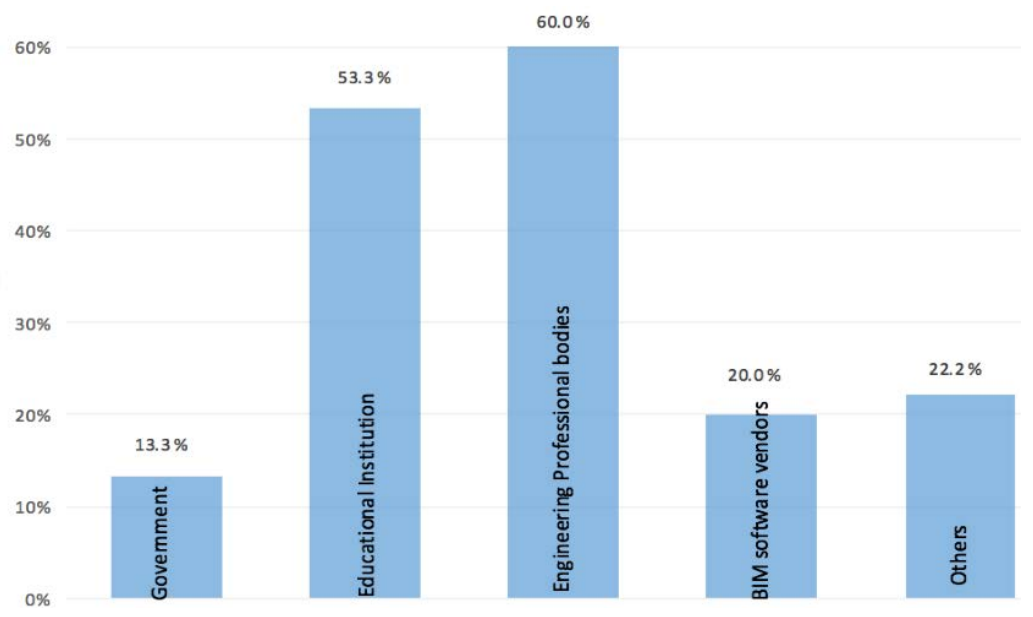

Fig. 4. Organizations responsible for BIM competence certification

All aspects of BIM competence were rated to be important. BIM skills (fluency in BIM applications) got a score of $90 \%$, BIM experience, including experience with BIM applications got a score of 78\%, and BIM knowledge, including awareness of BIM related developments got a score of $70 \%$.

In the open-ended question 9, respondents were asked to list 10 most important skills that are required for BIM professionals. Different skills were listed by the respondents, of which, the most common skills are listed in Table 2.

Table 2. Most important BIM skills as listed by the respondents

\begin{tabular}{|l|l|}
\hline Communication & Problem solving capabilities \\
\hline Leadership & Enthusiasm for learning \\
\hline
\end{tabular}




\begin{tabular}{|l|l|}
\hline Collaboration and coordination & Interoperability \\
\hline Process understanding & Time management \\
\hline LOD concept & Negotiation skills \\
\hline Application skills & Project management \\
\hline Knowledge about BIM standards and National BIM guidelines \\
\hline Experience in use of VDC/Big room Method \\
\hline \multicolumn{2}{|l|}{ Understanding about working environment of another discipline } \\
\hline
\end{tabular}

Section 2: BIM skills and competence

Section two of the survey mainly focused on BIM skills. The respondents' were given a pre-defined list of skills to rate as per their perceived importance. Although these questions were close-ended, the answers were not very different from the open-ended list created by the respondents in the previous section. In Question 10, respondents were able to choose the essential skills needed for BIM managers, Figure 5. The most valuable skills for BIM managers, as rated by the respondents, are collaboration, knowledge about BIM development, fluency in BIM applications, and technical skills.

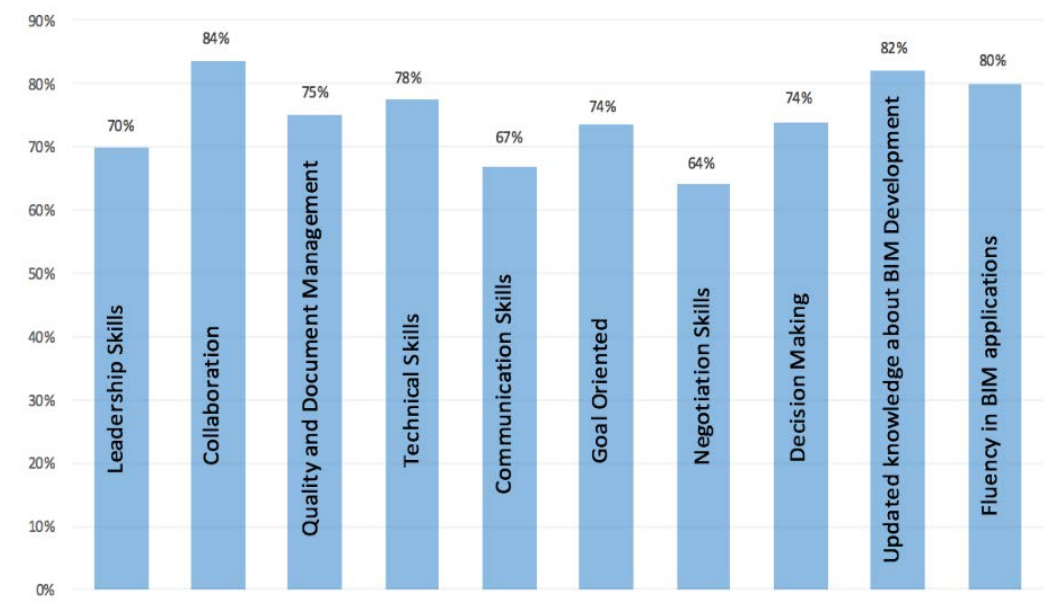

Fig. 5. Skill sets as per their importance for BIM Manager

For BIM coordinators the most important skills, based on the responses, Figure 6, are knowledge about BIM standards, and updated knowledge about BIM developments. The other important skills are leadership and application skills. Surprisingly, communication skills and creativity got relatively low ratings.

For BIM designer, the highest rated skills include updated knowledge of BIM development, application skills, and knowledge of BIM standards. The results show that BIM designers require BIM skills and BIM knowledge, Figure 7.

Question 13 asked about skills required in a BIM team. Based on the responses, the most important skills for a BIM team are coordination and collaboration, teamwork, and knowledge of BIM standards, Figure 8. 


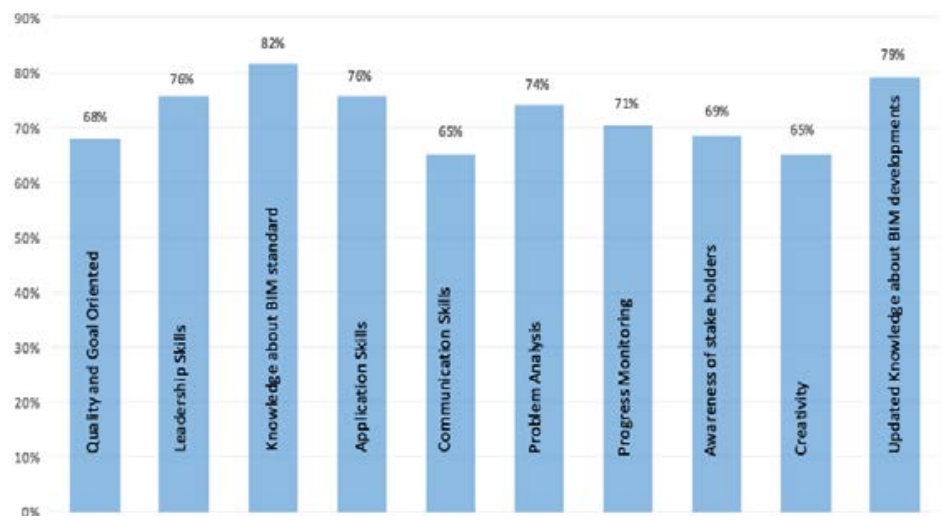

Fig. 6. Skill sets as per importance for BIM Coordinator

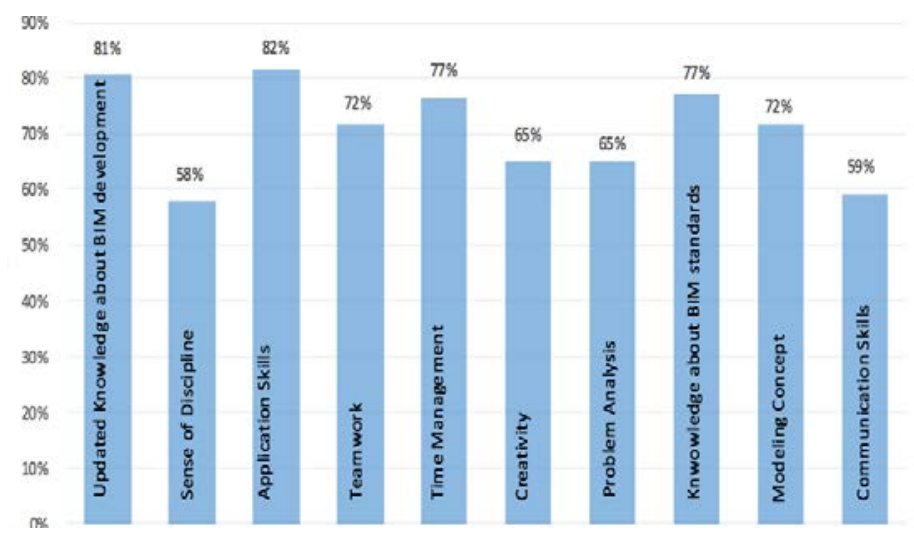

Fig. 7. Skill sets for BIM Designer as per their importance

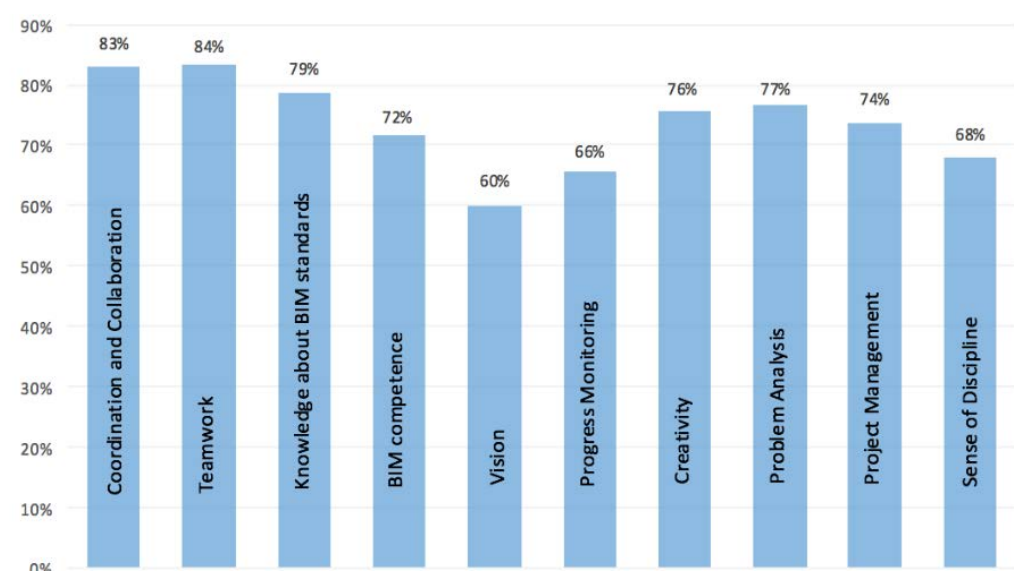

Fig. 8. Important skills for BIM Team. 
The last question asked the respondents to self-assess and report their own skills relevant to a BIM profession, Figure 9. The most commonly reported skills are coordination and collaboration, teamwork, application skills, knowledge about BIM standards, and modeling concepts, followed by problem analysis, time management, goal orientation, and leadership. The weakest self-assessed skill is related to creativity.

Figure 10 shows average, self-assessed skills and competences of the respondents.

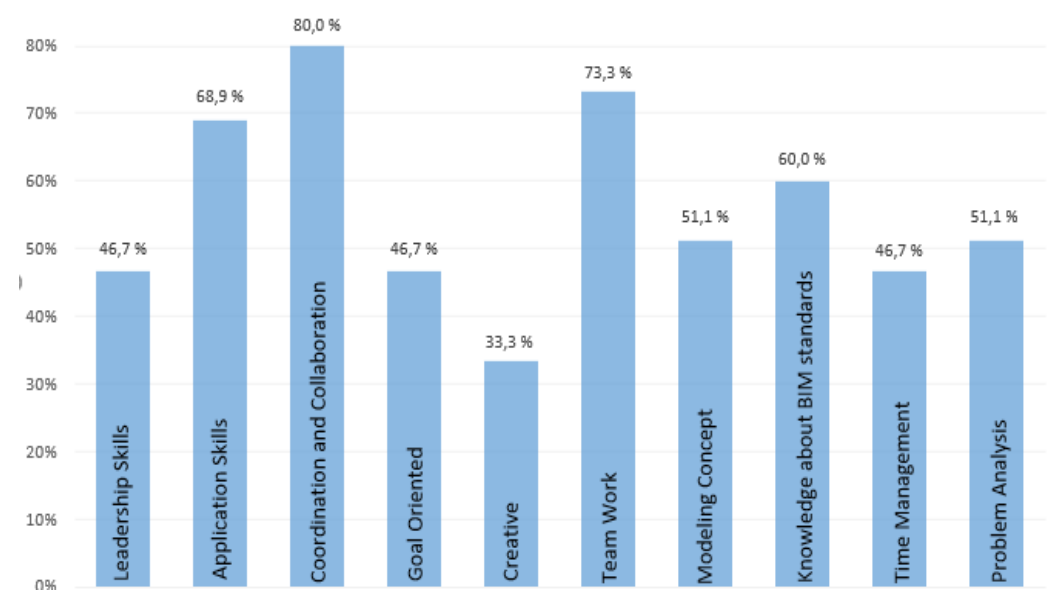

Fig. 9. BIM skills possessed by the respondents

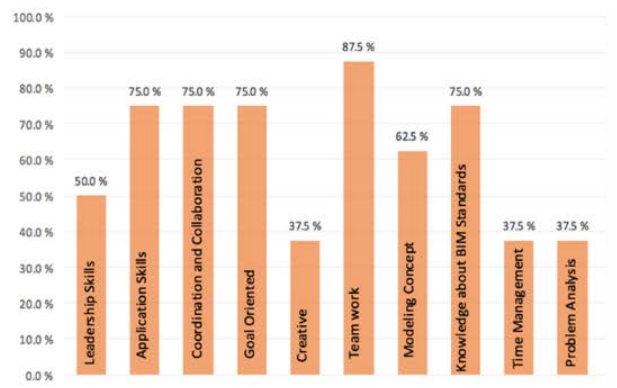

Bachelor's

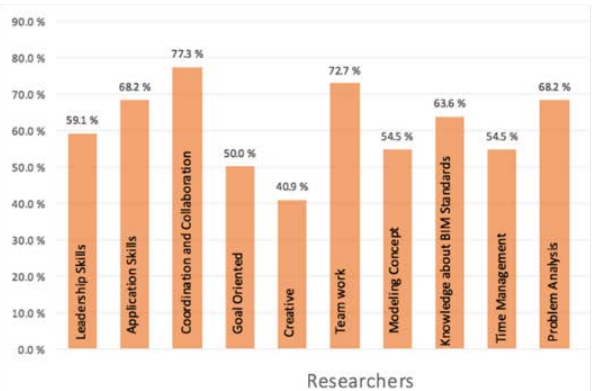

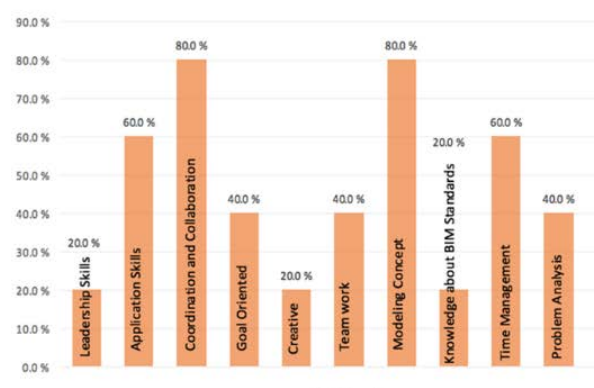

Master's

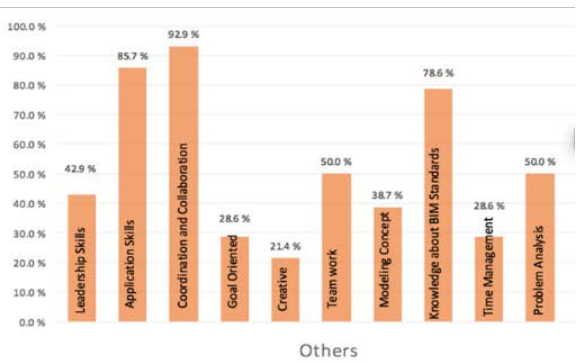

Fig. 5. BIM skills possessed by respondents as per their discipline 


\section{Discussion and conclusion}

Due to the recent and rapid increase in demand for BIM professionals, the current competence development, training, and educational practices are often based on reactive and adhoc planning, while a well-researched and time-tested best practice for diverse BIM competence requirements is yet to emerge. Therefore, we need structured understanding, assessment, and measurement of BIM competence of a person or a team, contingent on their role in the BIM ecosystem (Gu et al 2014).

This paper presents preliminary assessment of BIM competence requirements. At the core of our approach to assessing competence is the idea of profiles, which is a combination of skills. This means that even if two people have the same set of skills, their profiles could be very different from each other based on their level of competence in each of those skills. Similar conceptual approach has been proposed with respect to understanding multi-disciplinary expertise (Singh and Casakin 2015, Suwal et al 2016). This representation allows individuals and teams to self-assess their own unique profile, and assess how well they fair or compare with the typical profile expected for a particular job. For example, in Figure 10 we see how the profile of a typical bachelor student is different to the typical master student. An individual student can use this average to compare how they are similar or different to their peers. Such a comparison can, not only allow an individual to identify gaps in their own skill-sets, but it can also be used to strategically build their own unique profile that stands out from others.

In terms of the findings from the survey, there were a few surprises. For example, for BIM professionals such as BIM Managers, who lead a unit from the organization, the authors had expected that skills like leadership, communication, negotiation, and decision-making would be rated higher than what we found in the responses. Similarly, the survey results for BIM coordinator were opposite to what the authors had expected. Nonetheless, as expected collaboration and coordination are seen among the most important competencies required for BIM personnel as well as the BIM team.

Most participants in their feedback appreciated initiating a survey on this research topic. While the findings are only a preliminary study, further studies are planned to revise the questionnaire and the competencies listed in the current set.

\section{References}

1. Ahn, Y.H., Annie, R.P. and Kwon, H., (2012). Key competencies for US construction graduates: Industry perspective. Jo. of Prof. Issues in Eng. Edu. \& Practice, 138(2), pp.123-130

2. Barison, M.B., and Santos, E.T., (2011). The competencies of BIM specialists: a comparative analysis of the literature review and job ad descriptions. In Proc., Int. Workshop on Computing in Civil Engineering, ASCE, Reston, VA.

3. Davies, K., McMeel, D. and Wilkinson, S., (2015). Soft skill requirements in a BIM project team, Proc. of 32nd CIB W78 Conf., 27th-29th October 2015, Eindhoven, The Netherlands.

4. Dossick, C.S., Lee, N. and Foleyk, S., (2014). Building Information Modeling in Graduate Construction Engineering and Management Education. In ICCCBE 2014.

5. Eadie, R., Comiskey, D. and McKane, M., (2014). Teaching BIM in a multidisciplinary department. Proceeding of Education, Science and Innovations. 
6. Eastman et al., C., Teicholz, P., Sacks, R., and Liston, K., (2008) 'BIM Handbook: A Guide to Building Information Modeling for Owners, Managers, Designers, Engineers, and Contractors', John Wiley \& Sons, Inc., Hoboken, NJ, USA

7. Fan, S.L., Skibniewski, M.J. and Hung, T.W., (2014). Effects of building information modeling during construction. J. Appl. Sci. Eng, 17(2), pp.157-166.

8. Gillian, B and Kunz, J (2007). VDC Use in 2007: Significant Value, Dramatic Growth, and Apparent Business Opportunity, CIFE Technical Report \#TR171 Dec 2007

9. Mohd, S. and Ahmad Latiffi, A., (2013). Building Information Modeling (BIM) application in construction planning. 7th Int' Conf. on Constr. in the 21st Cent.(CITC-VII), Bangkok.

10. Rahman, R.A., Alsafouri, S., Tang, P. and Ayer, S.K., (2016). Comparing Building Information Modeling Skills of Project Managers and BIM Managers Based on Social Media Analysis. Procedia Engineering, 145, pp.812-819.

11. Singh, V. and Casakin, H. (2015). Developing a Computational Framework to Study the Effects of Use of Analogy in Design on Team Cohesion and Team Collaboration. 20th Int'l Conf. on Eng. Design (ICED15), Milan, July 27-29. Weber, et al. (eds.), pp. 101-110.

12. Succar, B., Sher, W. and Williams, A., (2013). An integrated approach to BIM competency assessment, acquisition, and application. Automation in Construction, 35, pp.174-189.

13. Succar, B., and Sher, W., (2014), April. A competency knowledge-base for BIM learning. In Australasian Jo. of Constr. Eco. and Building-Conf. Series, Vol. 2, No. 2, pp. 1-10.

14. Succar, B., Sher, W. and Williams, A., (2012). Measuring BIM performance: Five metrics. Architectural Engineering and Design Management, 8(2), pp.120-142.

15. Suwal, S., Singh, V. and Shaw, C. (2016). Towards a Framework to Understand Multidisciplinarity in BIM Context - Education to Teamwork, CIB World Building Cong., 658-672.

16. Taiebat, M. and Ku, K. (2010). Industry's Expectations of Construction School Graduates' BIM Skills, Proceedings of ASC conference, Boston, 2010

17. Wei, W.U., and Raja, R.A., (2014). Key issues in workforce planning and adaptation strategies for BIM implementation in construction industry, Constr. Research Cong. 2014.

18. Yarmohammadi, S., and Ashuri, B., (2015). Exploring the approaches in the implementation of BIM-based MEP coordination in the USA, Journal of IT in Constr., Sept. 2015.

19. Yalcinkaya, M. and Singh, V., 2015. Patterns and trends in Building Information Modeling (BIM) research: A Latent Semantic Analysis. Automation in Construction, 59, pp.68-80 